\title{
Helium Irradiation Effects on the Surface Modification and \\ Recrystallization of Tungsten
}

\author{
A. Khan ${ }^{\mathrm{a}}$, G. De Temmerman ${ }^{\mathrm{b}}$, S. Kajita ${ }^{\mathrm{c}}$, H. Greuner ${ }^{\mathrm{a}}$, M. Balden ${ }^{\mathrm{a}}$, K. Hunger ${ }^{\mathrm{a}}$, N. Ohno ${ }^{\mathrm{d}}$, D.

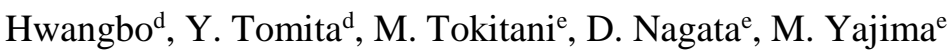 \\ ${ }^{a}$ Max Planck Institute for Plasma Physics, Boltzmannstr. 2, D-85748 Garching \\ ${ }^{\mathrm{b}}$ ITER Organization, Route de Vinon-sur-Verdon - CS 90046 - 13067 St Paul Lez Durance Cedex - \\ France \\ c IMaSS (Institute of Materials and Systems for Sustainability), Nagoya University, Nagoya 464- \\ 8603, Japan \\ ${ }^{\mathrm{d}}$ Graduate School of Engineering, Nagoya University, Nagoya 464-8603, Japan \\ ${ }^{e}$ National Institute for Fusion Science, Oroshi 322-6, Toki 509-5292, Japan
}

\begin{abstract}
Helium (He) irradiation has previously been observed to alter surface modifications and the recrystallization properties of tungsten (W). In this study, He irradiations in the NAGDIS-II linear plasma device, at temperatures below recrystallization and low energies $(50 \mathrm{eV})$ followed by annealing at $1470 \mathrm{~K}$ were carried out. Additionally, high energy $(28 \mathrm{keV})$ hydrogen $(\mathrm{H})$ with an admixture of 6 at $\%$ He irradiations in the neutral beam facility GLADIS were performed at temperatures above recrystallization $(1770 \mathrm{~K})$. These are compared to pure $\mathrm{H}$ irradiations under the same conditions. In the low temperature cases, following irradiation, an undulating microstructure is observed on the surface of the samples after irradiation. After annealing at $1470 \mathrm{~K}$, it is observed that the inhibition effect of He irradiation is more pronounced following lower temperature exposures. The effect of He irradiation on inhibition of recrystallization with grain growth is also observed to saturate at the highest fluences. In the high temperature, high energy case, He irradiation and recrystallization happens simultaneously. Following the irradiation a coral like microstructure is observed on the surface of the sample. The introduction of $\mathrm{He}$ is not seen to have a significant effect on the recrystallization process of $\mathrm{W}$ when the irradiation is carried out at temperatures above recrystallization.
\end{abstract}




\section{Introduction}

In ITER, the high heat and particle fluxes in the divertor will lead to surface temperatures on the tungsten plasma-facing material possibly exceeding those at which recrystallization and grain growth occur. Recrystallization is known to lead to a modification of the mechanical properties of the material and has been shown to increase the probability of the formation of macro-cracks during high heat flux testing at $20 \mathrm{MW} / \mathrm{m}^{2}[1,2]$. Recent observations indicate that exposures to a high flux plasma could alter the recrystallization kinetics of tungsten [3-5]. In particular, helium plasma exposure has been shown to make tungsten surfaces more resistant to recrystallization and grain growth $[3,6]$, presumably because of the effect helium has on the mobility of grain boundaries. In view of ITER operation, where $\mathrm{W}$ recrystallization poses potential serious issues, it is important to identify the necessary conditions for retarded recrystallization to occur (surface temperature, particle species, flux, fluence, etc) and to clarify what is the driving mechanism. Most studies so far have been done in linear plasma devices at temperatures lower than the recrystallization temperature. This article aims to further investigate the effect of He irradiation on surface modifications and recrystallization properties of tungsten. The effect of surface temperature and ion fluence is studied in the NAGDIS-II linear plasma device [7]. The plasma exposure is then followed by vacuum annealing to induce recrystallization. In addition, experiments have been done with a higher energy neutral beam in the GLADIS high heat flux test facility [8] at high surface temperature to study the case where the He ion exposure and the recrystallization process are expected to occur simultaneously.

\section{Samples and loading conditions}

He plasma exposures were performed in the NAGDIS-II device at the following parameters: $\sim 50 \mathrm{eV}$ He ion energy, ion flux in the range $1.5-3.5 \times 10^{22} \mathrm{~m}^{-2} \mathrm{~s}^{-1}$ and fluences in the range $0.2-4.6 \times 10^{26} \mathrm{~m}^{-2}$. The surface temperatures $\mathrm{T}_{\text {surf }}$ during loading were varied from 600 to $823 \mathrm{~K}$. The energy was controlled through biasing the sample and a Langmuir probe was used to measure the plasma parameters [7]. The exposure conditions are listed in Table 1.

The tungsten samples (10 mm diameter, $0.5 \mathrm{~mm}$ thickness, purity $99.95 \%$.) were produced by A.L.M.T. (Japan). The surface was mechanically polished to obtain a roughness of $0.05 \mu \mathrm{m}$. The 
samples had an inhomogeneous microstructure with an average grain size of $\sim 3.5 \mu \mathrm{m}$. After plasma exposure, all samples, including a non-exposed reference sample, were annealed for 1 hour at $1473 \mathrm{~K}$. A temperature close to the beginning of recrystallization was chosen because previous work has shown that annealing at higher temperatures only show marginal differences in recrystallization [3]. The average grain sizes were obtained from EBSD measurements (Figure 1), using a misorientation threshold of $15^{\circ}$, where the average took into account the area fraction covered by the grains (a normalised value for the area covered by grains of a certain diameter).

Table 1: Experimental conditions for He plasma exposures in NAGDIS-II

\begin{tabular}{|l|l|l|l|}
\hline Sample Name & Temperature $(\mathrm{K})$ & Fluence $\left(\mathrm{m}^{-2}\right)$ & Exposure Time (s) \\
\hline N600_2x25 & 600 & $1.9 \times 10^{25}$ & 1140 \\
\hline N600_1x26 & 600 & $1.0 \times 10^{26}$ & 4680 \\
\hline N823_2x25 & 823 & $1.9 \times 10^{25}$ & 660 \\
\hline N823_1x26 & 823 & $1.0 \times 10^{26}$ & 6000 \\
\hline N823_5x26 & 823 & $4.6 \times 10^{26}$ & 16200 \\
\hline
\end{tabular}

The $\mathrm{H} / \mathrm{He}$ exposures at higher energies were performed in the GLADIS facility. The samples investigated in this paper were from a larger series of exposures carried out $[9,10]$. The $5 \times 10 \times 15$ $\mathrm{mm}^{3} \mathrm{~W}$ blocks were cut from forged rods (99.97\% purity) produced by PLANSEE SE (Austria). This manufacturing process resulted in a variation of the microstructure with typical grain sizes between 2$5 \mu \mathrm{m}$ (Figure 4). The samples were brazed onto a $\mathrm{Cu}$ heat sink to allow a temperature control by active cooling during exposure. The surfaces of the samples were polished to a mirror finish.

The samples were exposed to pure $\mathrm{H}$ and mixed $\mathrm{H} / 6 \% \mathrm{He}$ beams to investigate surface morphology modification, occurring during high heat flux loading using $\mathrm{H}$ and $\mathrm{He}$ particles or to a pure $\mathrm{H}$ neutral beam as a reference. These experiments simulate the expected operation conditions of plasma-facing materials with a He "ash" content of about $5 \%$ in future fusion devices [11,12]. In the pure $\mathrm{H}$ loading case, the ion species distribution of the beam source resulted in target loading with $22 \%$ of atoms of a 
full energy, $\mathrm{E},=28 \mathrm{keV}, 43 \%$ of $1 / 2 \mathrm{E}$ and $35 \%$ had an energy of $1 / 3 \mathrm{E}$, resulting in a mean particle energy of $15 \mathrm{keV}$. In case of $\mathrm{H} / 6 \% \mathrm{He}$ loading the particle energy and distribution is similar; $21 \% \mathrm{H}$ at $\mathrm{E}=28 \mathrm{keV}, 40 \% \mathrm{H}$ at $\mathrm{E} / 2,33 \% 1 / 3 \mathrm{E}, 6 \% \mathrm{He}$ at $28 \mathrm{keV}$. More details about the loading conditions can be found in reference [10]. The exposures were performed with $30 \mathrm{~s}$ pulses. Since the samples reached the thermal equilibrium after about $7 \mathrm{~s}$, the samples were loaded under steady-state condition for the remaining $23 \mathrm{~s}$ of each pulse. The particle fluxes were of the order of $4 \times 10^{21} \mathrm{~m}^{-2} \mathrm{~s}^{-1}$. Table 2 summarizes further details of the loadings.

The energies employed in GLADIS are above the sputtering threshold of $\mathrm{W}$ by $\mathrm{He}(120 \mathrm{eV})$ and also W by $\mathrm{H}(460 \mathrm{eV})$ [13]. Note the energies used in NAGDIS-II are below the sputtering threshold of W by He. The applied surface heat flux of $10 \mathrm{MW} / \mathrm{m}^{2}$ simulates the typical heat load during steady state operation of ITER divertor plasma-facing units, resulting in predicted surface temperatures up to 1100 ${ }^{\circ} \mathrm{C}$ [14]. Previous work has shown that with the admixture of $6 \% \mathrm{He}$ to the $\mathrm{H}$ beam, it is the fluence of He and the surface temperature that drive modifications to the surface microstructure of $\mathrm{W}[11,15]$. Therefore, the high energy experiments are comparable to the lower energy experiments. The pure $\mathrm{H}$ loading was performed as reference. No strong surface morphology changes, except due to recrystallization, were expected.

Table 2: GLADIS exposure conditions

\begin{tabular}{|l|l|l|l|l|}
\hline Loading & $\begin{array}{l}\text { Temperature } \\
(\mathrm{K})\end{array}$ & Fluence $\left(\mathrm{m}^{-2}\right)$ & Exposure time (s) & No of pulses \\
\hline $\mathrm{H}$ Pure & 1773 & $1 \times 10^{25}$ & 2640 & 88 \\
\hline $\mathrm{H} / 6 \% \mathrm{He}$ & 1773 & $2 \times 10^{25}$ & 5363 & 180 \\
\hline
\end{tabular}

Following the exposure, SEM assisted by FIB to prepare cross sections (Helios Nanolab 600, FEI; 5 $\mathrm{keV}$ electron beam energy) was used to analyse changes to the surface and microstructure. Secondary electrons (SE) and back scattered electrons (BSE) were used for imaging. Grain sizes were obtained from EBSD data (Hitachi nanoDUE'T NB5000) and SEM image analyses for the NAGDIS-II and the GLADIS exposed samples, respectively. 


\section{Results and Discussion}

\subsection{Low energy plasma exposure}

After all the plasma exposures in NAGDIS-II, the surface of the samples retained a shiny metallic appearance, however, when analysed in the SEM, it was observed that there were some microscale topological modifications on the surface of all samples (Figure 1). The modification varies between different grains and is seen to be most pronounced on the sample exposed to the highest temperature and fluence (N823_5x26). The He ion energy and fluences during these experiments are within the typical range where fuzz formation was observed in linear plasma devices [16], however, the temperature is below that required for fuzz formation and unlike fuzz, these structures appear to be more periodic, repeating at regular intervals across the grains [17]. The structure that is seen in these exposures is an undulating structure that has been observed previously, although the formation mechanism is not agreed on [18-20]. In the literature, FIB-prepared cross sections of such undulating structures have revealed He nano-bubbles close to the surface, with the thickness of the layer of bubbles much greater than the implantation depth of He in W [19]. Research by Miyamoto et al. has shown that the size of such He bubbles increases with exposure temperature and that there is a saturation of the density of He bubbles at a fluence of $5 \times 10^{23} \mathrm{~m}^{-2}$ [19]. Similar undulating structures have also been observed following exposures of W to deuterium (D) [21]. Mass losses for the samples in this study was in the range of 4-20 $\mu \mathrm{g}$, indicating some sputtering from impurities in the plasma beam. In a $10 \mathrm{~mm}$ sample, this corresponds to a $15 \mathrm{~nm}$ erosion depth.

After the plasma exposure, all the samples, as well as reference sample were annealed for 1 hour at $1473 \mathrm{~K}$. After annealing, the surface modifications seen on the surface of the samples post irradiation had disappeared (Figure 2). Cross sections prepared by FIB, do not reveal bubbles below the surface in the SEM (Figure 2). Annealing of He induced surface modifications has been previously observed in the literature [3]. Reduced grain growth on the surface of the He exposed samples is observed compared to the reference sample. In numbers, the reference sample, has grains with an average grain size of $32.8 \pm 14.4 \mu \mathrm{m}$ after annealing. It appears that the majority of the surface of the reference sample is covered in newly formed larger grains, with some small pockets of smaller grains. The 
average grain size of the He plasma exposed samples after annealing was 0.5-0.8 times that of the reference sample (Figure 1), with the exception of the sample N823_2x25, where the average grain size was even slightly larger than for the reference sample. However, it should be noted that the error bars in such measurements are large due to the broad grain size distribution. The grain size distribution of all the He exposed samples as well as of the annealed reference sample are shown in Figure 3. It can be seen that typically the plasma exposed samples have a higher area fraction covered by small grains in comparison to the reference sample.

In detail, sample N600_2x25 has an average grain size of $\sim 50 \%$ of the non-exposed annealed sample and sample N600_1x26 has an average grain size of $~ 75 \%$ of the non-exposed sample. The inhibition of recrystallization at $600 \mathrm{~K}$ is in agreement with previous work carried out by Guo et al. at similar temperatures [3]. At $823 \mathrm{~K}$ the grain size decrease with fluence, with an apparent saturation at the two highest fluences. Sample N823_2x25 has an average grain size that is almost the same as the nonexposed annealed sample. Samples N823_1x26 and N823_5x26 have average grain sizes that are 73 and $84 \%$ of the non-exposed annealed sample, respectively. At higher temperatures, the inhibition of recrystallization is less severe, in agreement with Song et al. [6].

Cross sections were prepared by FIB on the samples after annealing. Two cross sections on the sample exposed to a He plasma up to a fluence of $1.9 \times 10^{25} \mathrm{~m}^{-2}$ at $823 \mathrm{~K}$ are shown in Figure 2 as an example. It is interesting to note that there is a significant affected layer, of the order of microns (typically a few grains in thickness), however, the affected zone extends deeper than the penetration depth of $50 \mathrm{eV} \mathrm{He}$ in $\mathrm{W}$. The inhibition of recrystallization is inhomogeneous across the sample, resulting in a mix of large recrystallized grains and smaller deformed grains as observed in Figure 2, at the FIB cross sections. Although cross sections before annealing were not carried out, in the literature $\mathrm{He}$ bubbles have been observed at depths exceeding the implantation of depth of $\mathrm{He}$ in $\mathrm{W}$, but still of the order of tens of nanometres [19].

The mechanism of inhibition may be due to trapping of He in the initial tens of nanometres into the sample, which may impede grain boundary motion. This affects the whole grain. In the literature it 
has been shown that the size and density of He bubbles formed is influenced by the incident fluence and temperature, Song et al. [6] have shown that with increased temperatures, helium nano-bubbles increase in size. Miyamoto et al. observed a saturation in He bubble density at fluences greater than $5 \times 10^{23} \mathrm{~m}^{-2}$ [19]. The Zener-pinning effect, has been suggested by Song et al. [6] as a mechanism to describe the less inhibited recrystallization observed following higher temperature He exposures in comparison to lower temperature ones. Due to the fact that the He bubble size increases with higher temperatures, the Zener-pinning effect means that there is a reduction in the drag force, the grain boundary motion is less slowed, and hence the inhibition of the recrystallization process is not as significant as in the lower temperature cases. At fluences of $1.9 \times 10^{25}$, the same temperature effect observed by Song et al. is also seen, but at higher fluences this is not observed. The bulk of the material is not affected by the He irradiation, only by the heat load. In this investigation the He exposure and annealing were performed sequentially, and it is important to see if the same effects are observed when annealing and exposure occur simultaneously.

\subsection{Higher energy particle exposure}

The microstructural modifications on the surface of the two samples exposed in GLADIS are completely different. The microstructures after the pure $\mathrm{H}$ as well as the $\mathrm{H} / 6 \% \mathrm{He}$ loading show a larger grain size in comparison to the starting material. The average grain size of the $\mathrm{H}$ exposed sample is $70 \pm 18 \mu \mathrm{m}$ and that of the $\mathrm{H} / 6 \% \mathrm{He}$ exposed sample was $60 \pm 12 \mu \mathrm{m}$. On the $\mathrm{H}$ exposed samples there are some larger grains, but also some smaller grains are still visible on the surface. There is no significant difference due to the presence of the He admixture on the recrystallization and grain growth effects. Unlike in the low energy and low surface temperature cases, where pockets of small grains are observed in the first few microns into the depth of the sample, this is not observed in the higher energy and higher surface temperature cases because at $1773 \mathrm{~K}$ the sample is clearly in the grain growth stage. Additionally, as observed by Song et al.[6] the effect of He irradiation on inhibition of recrystallization is not as severe when the He exposure is performed at higher temperatures. If we extrapolate this to higher temperatures, the results from the high energy exposures are in line with this literature, with no significant effect seen. 
On the surface of the $\mathrm{H}$ exposed sample, we observe 1-2 $\mu$ m diameter 'holes' across the surface (Figure 5 a)), which is confirmed in the FIB cross sections (Figure 5 b)). Pores are visible up to a few microns below the surface. Pores are typically seen below the surface in the tungsten material exposed to $\mathrm{H}$ neutral beams in GLADIS, but not in as high a quantity as observed in this case. In the FIB cross sections there also appears to be pores close to the surface and also several microns below the surface. The diameters of the pores vary from tens of nanometres to $\sim 350 \mathrm{~nm}$. Again, the region of damage appears to extend deeper than the penetration depth of the maximum energy of $28 \mathrm{keV} \mathrm{H}$ in $\mathrm{W}$, as calculated by SRIM, which is $\sim 120 \mathrm{~nm}$ [22]. The thickness of the eroded layer due to physical sputtering on this sample was calculated to be $\sim 300 \mathrm{~nm}[10,13]$. Apart from the holes, the surface of the sample still appears to be fairly flat after irradiation (Figure $5 \mathrm{~b}$ )).

In contrast we see the development of a coral like nanostructure on the surface of the $\mathrm{H} / 6 \% \mathrm{He}$ irradiated sample (Figure $5 \mathrm{c}$ ), d)). The surface is uneven and there are many cavities observed near to the surface. There are two main types of cavities, those with a diameter of a few tens of nanometres and those that are a few hundreds of $\mathrm{nm}$ in diameter (Figure $5 \mathrm{~d}$ )). This has also been analysed in more detail in [10]. The thickness of the surface layer with cavities is several hundreds of nanometres. This exceeds the penetration depth of $28 \mathrm{keV} \mathrm{He}$ or $\mathrm{H}$ in $\mathrm{W}$ (74 nm and $120 \mathrm{~nm}$ respectively), as calculated by SRIM [22]. The thickness of the eroded layer due to physical sputtering on this sample was calculated to be $\sim 1.3 \mu \mathrm{m}[10,13]$. The formation of such a coral like structure has previously been observed in GLADIS for exposures to pure He [23,24]. An addition of only $6 \% \mathrm{He}$ results in surface modifications similar to those observed to similar high energy pure He exposures. In agreement with previous studies [10], it is the absolute He fluence of $1.2 \times 10^{24} \mathrm{~m}^{-2}$ that is responsible for the coral like modifications..

In GLADIS the He exposure and heating occur simultaneously. An exposure to a H/6\%He neutral beam is compared to a pure $\mathrm{H}$ neutral beam exposure at $1773 \mathrm{~K}$. The fluences were 2 and $1 \times 10^{25} \mathrm{~m}^{-2}$, respectively. The influence of $\mathrm{He}$ on recrystallization is not seen to be significant, and it is suggested that this is due to the higher temperatures employed. Again, as in the low energy case, the He loading only influences the first few $\mu \mathrm{m}$, with the bulk only being influenced by the heat load itself. 


\section{Summary}

From the $\mathrm{H} / \mathrm{He}$ irradiation experiments performed at low and high temperatures for two different energies at $50 \mathrm{eV}$ and $28 \mathrm{keV}$ it is observed that the He irradiation effect only influences the tungsten material up to a depth of several $\mu \mathrm{m}$. In the low energy, low temperature cases, the inhibition of grain growth is seen to be greater after He exposures at $600 \mathrm{~K}$ in comparison to $823 \mathrm{~K}$, in agreement with Song et al. [6]. The inhibition effect on recrystallization is observed to saturate at higher fluences. For the simultaneous heat and particle loading at higher energy and surface temperatures, the admixture of He does not significantly inhibit the grain growth. It is suggested that this could be due to the higher temperatures employed for the irradiation experiments. There is never any effect deeper than several $\mu \mathrm{m}$ into the material, irrespective of whether we do the sequential approach as performed in the $50 \mathrm{eV}$ low energy plasma loading or the simultaneous approach performed during the $28 \mathrm{keV} \mathrm{H} / \mathrm{He}$ neutral particle loading. It is clear in both cases that the He irradiation results in surface modifications of W, with a more severe modification at the higher temperature and the higher energies, above the sputtering threshold.

\section{Acknowledgments}

"This work has been carried out within the framework of the EUROfusion Consortium and has received funding from the Euratom research and training programme 2014-2018 and 2019-2020 under grant agreement No 633053. The views and opinions expressed herein do not necessarily reflect those of the European Commission or of the ITER Organization.” 
$5 \quad$ Figures

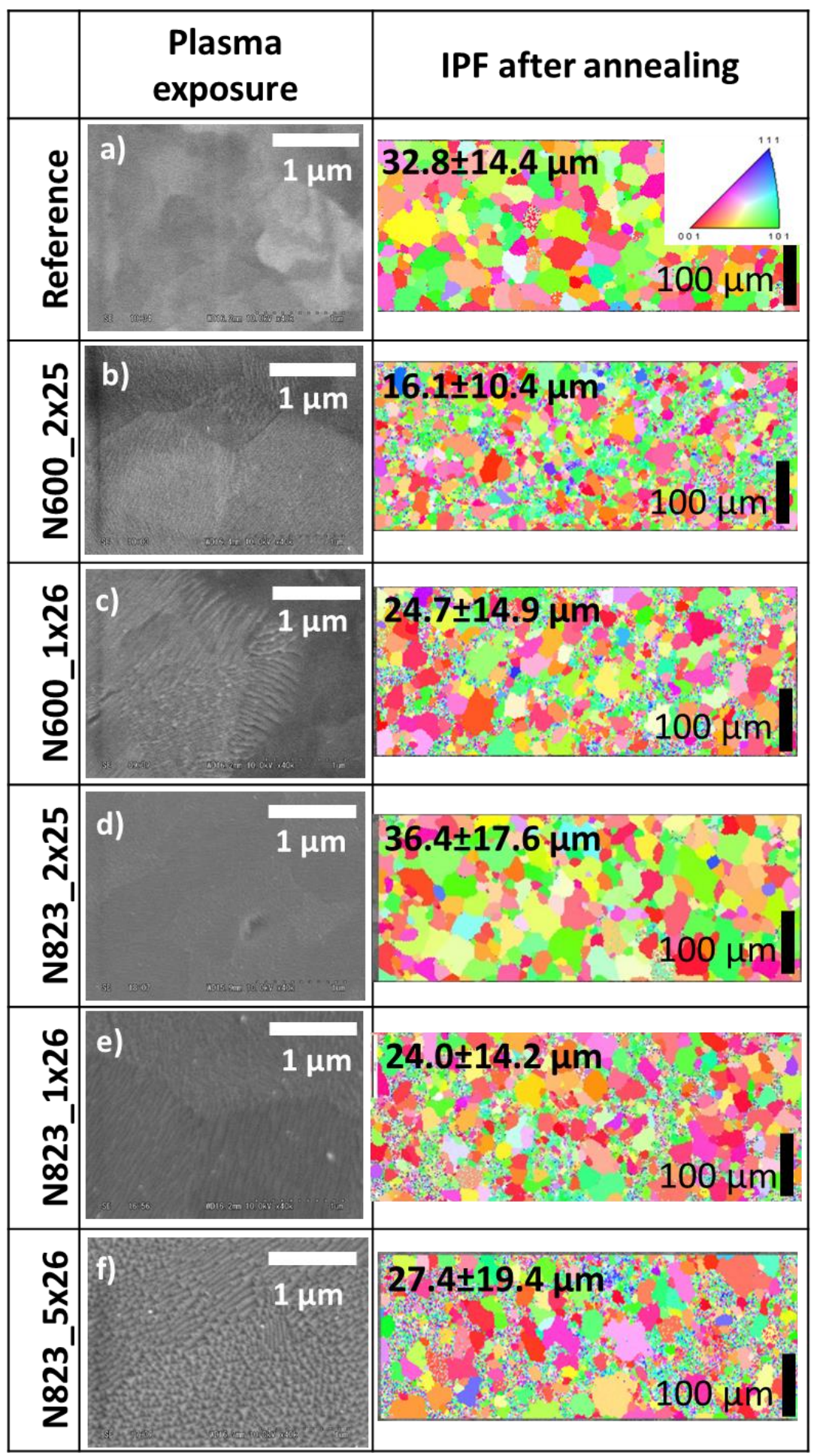

Figure 1: Secondary electron images after He exposure and orientation maps (colour-coded equal to the inverse pole figure (IPF) for the surface normal direction given in a)) after additional annealing for 1 hour at $1473 \mathrm{~K}$ are given for a) the as-received material, after He plasma exposure at fluences of b) $1.9 \times 10^{25}$ and c) $1.0 \times 10^{26} \mathrm{~m}^{-2}$ at a temperature of $600 \mathrm{~K}$ and at fluences of d) $1.9 \times 10^{25}$, e) $1.9 \times 10^{26}$ and f) $4.6 \times 10^{26} \mathrm{~m}^{-2}$ at a temperature of $823 \mathrm{~K}$. The EBSD data are used to obtain the mean grain size which are given above the orientation maps. For the as-received samples, the grains size is $3.5 \pm 2.6 \mu \mathrm{m}$. 

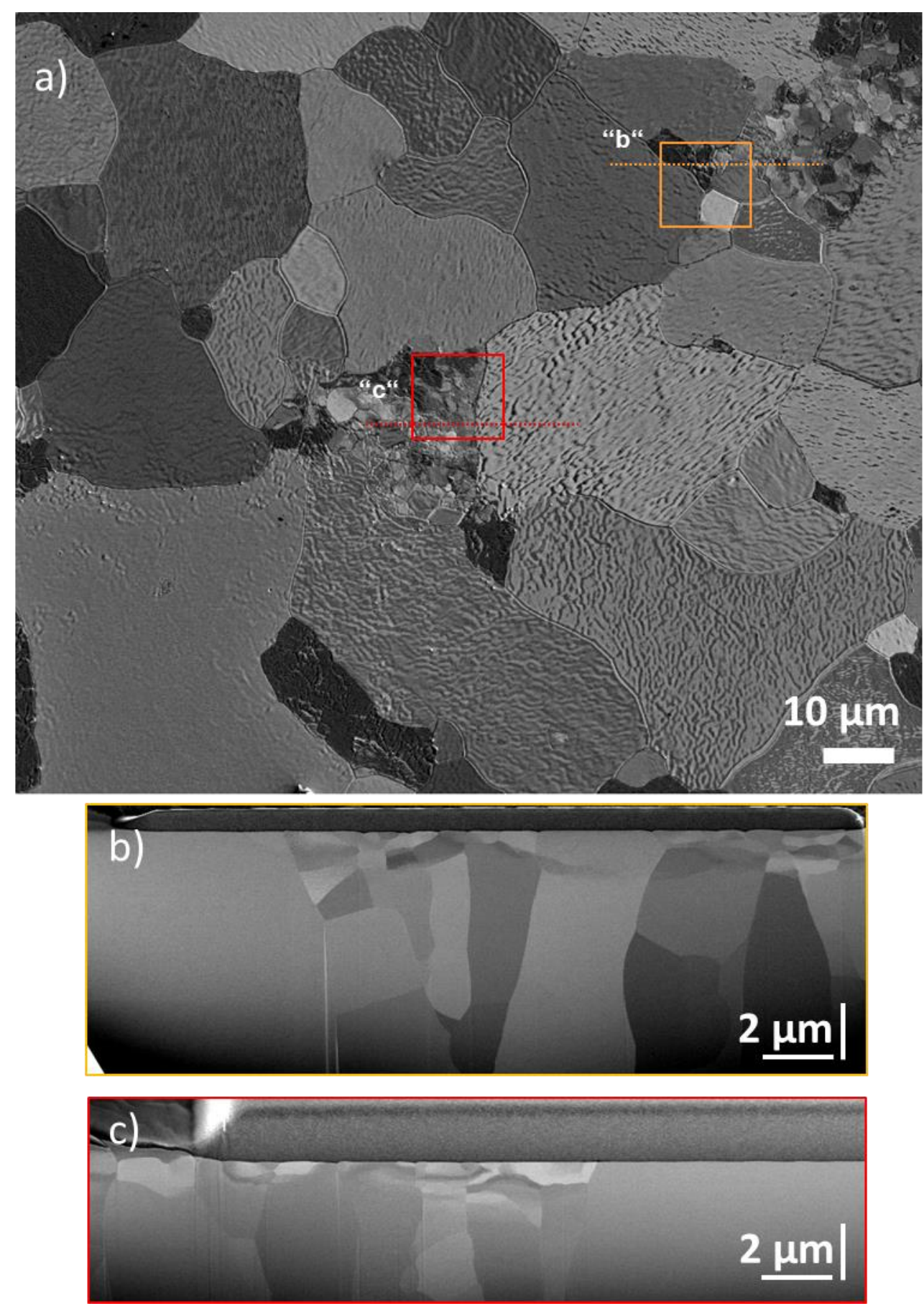

Figure 2: FIB cross sections in two positions on sample exposed to He plasma to a fluence of $1.90 \times 10^{25} \mathrm{~m}^{-2}$ at $823 \mathrm{~K}$ after annealing at $1473 \mathrm{~K}$ for 1 hour. The surface view (a) is untilted and the cross sections $(b, c)$ are viewed under an angle of $38^{\circ}$ (secondary electron images). The recrystallization of deeper material is not affected from the He exposure. The material is not yet fully recrystallized. 

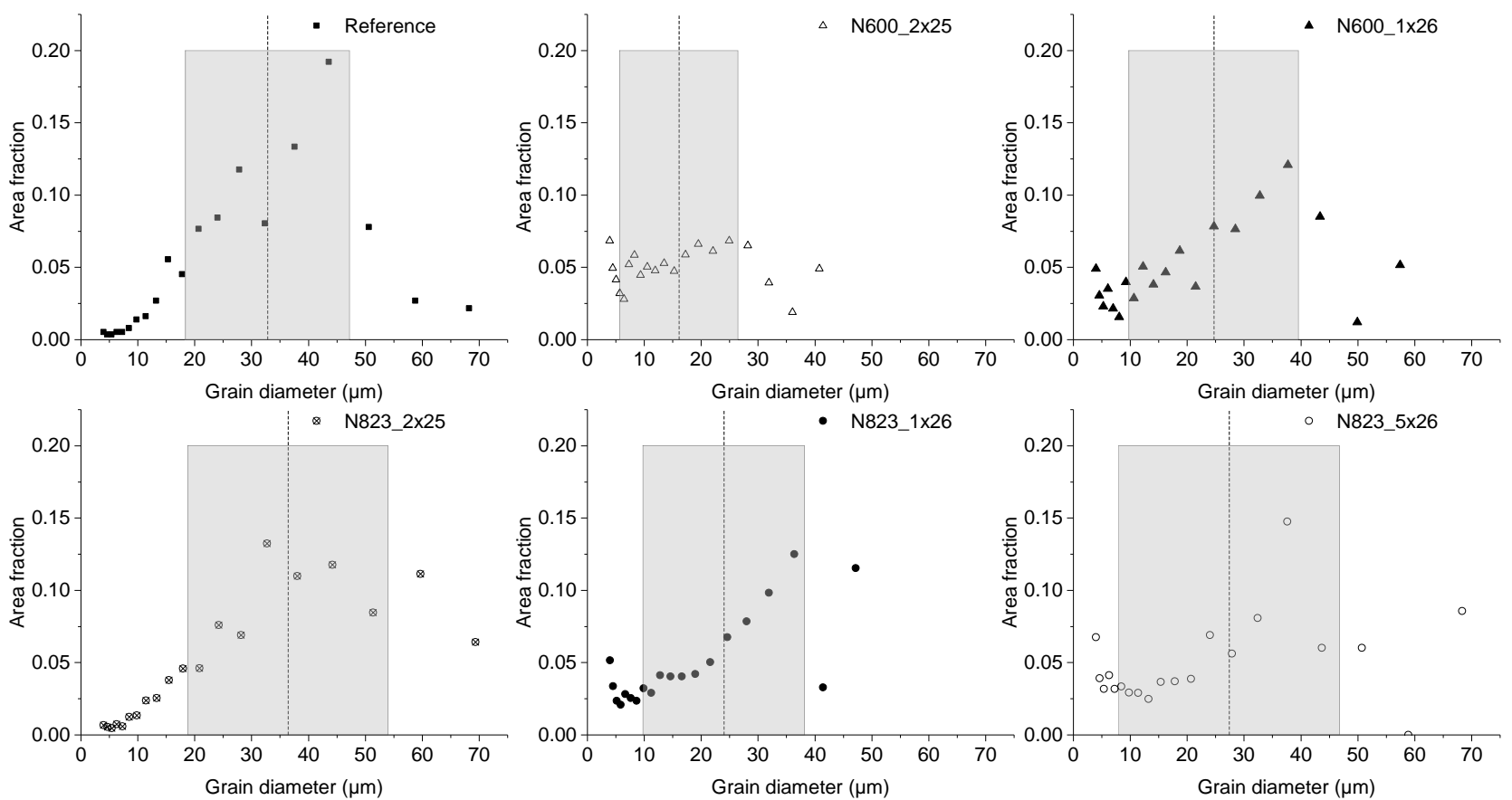

Figure 3: Grain size distribution for $50 \mathrm{eV}$ He plasma exposed samples, and a reference sample after annealing for one hour at $1473 \mathrm{~K}$. The mean grain size is shown as a dashed line in each case and the grey box shows the standard deviation.

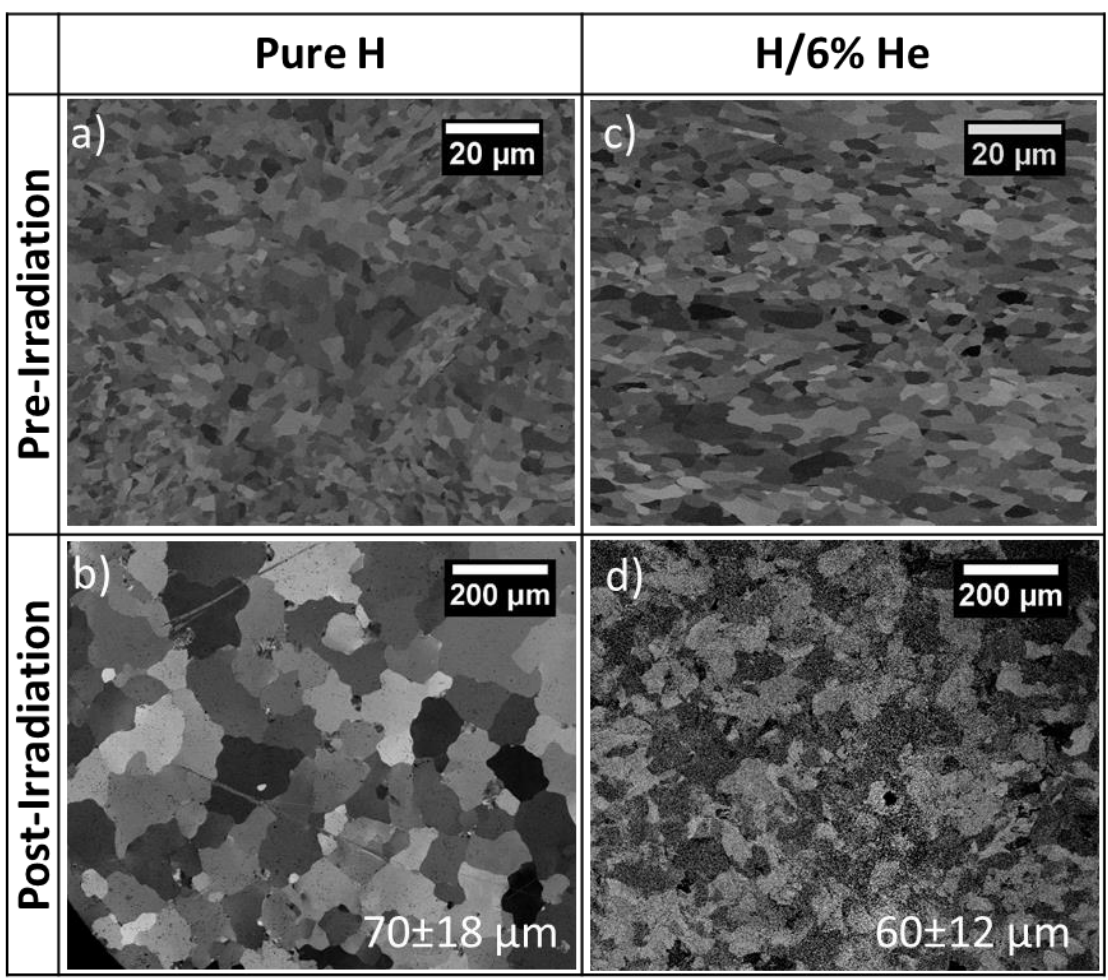

Figure 4: Low magnification back scattered electron SEM images of $W$ samples (a) before and (b) after exposure to pure $\mathrm{H}$ neutral beam up to a fluence of $1 \times 10^{25} \mathrm{~m}^{-2}$ and (c) before and (d) after exposure to $\mathrm{H} / 6 \% \mathrm{He}$ neutral beam up to a fluence of $2 \times 10^{25} \mathrm{~m}^{-2}$ at $1773 \mathrm{~K}$. The typical grain size of the starting material is between $2-5 \mu \mathrm{m}$. The average grain size post-irradiation is given in the bottom right of the image. 


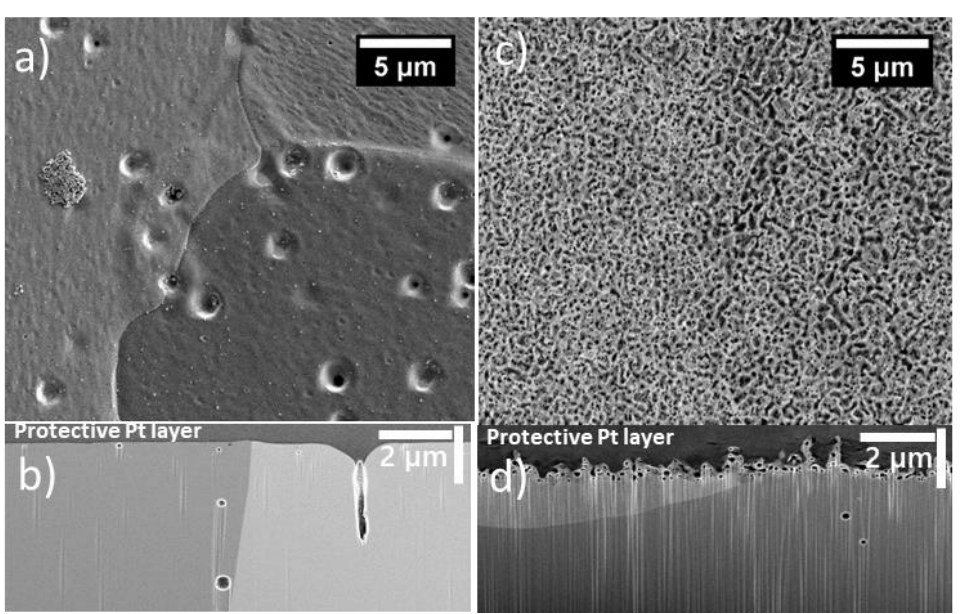

Figure 5: Higher magnification SEM images and FIB-prepared cross sections of $W$ samples exposed to a), b) pure $H$ neutral beam up to a fluence of $1 \times 10^{25} \mathrm{~m}^{-2}$ and c), d) $\mathrm{H} / 6 \% \mathrm{He}$ neutral beam up to a fluence of $2 \times 10^{25} \mathrm{~m}^{-2}$ at $1773 \mathrm{~K}$. The cross sections b), d) are viewed under an angle of $38^{\circ}$. All images are obtained by secondary electrons except (c) which is obtained by backscattered electrons.

\section{References}

[1] S. Panayotis, T. Hirai, V. Barabash, A. Durocher, F. Escourbiac, J. Linke, T. Loewenhoff, M. Merola, G. Pintsuk, I. Uytdenhouwen, M. Wirtz, Nucl. Mater. Energy 12 (2017) 200-204.

[2] T. Hirai, S. Panayotis, V. Barabash, C. Amzallag, F. Escourbiac, A. Durocher, M. Merola, J. Linke, T. Loewenhoff, G. Pintsuk, M. Wirtz, I. Uytdenhouwen, Nucl. Mater. Energy 9 (2016) $616-622$.

[3] W. Guo, L. Cheng, G. De Temmerman, Y. Yuan, G.H. Lu, Nucl. Fusion 58 (2018) 106011.

[4] T. Loewenhoff, S. Bardin, H. Greuner, J. Linke, H. Maier, T.W. Morgan, G. Pintsuk, R. a. Pitts, B. Riccardi, G. De Temmerman, Nucl. Fusion 55 (2015) 123004.

[5] T.W. Morgan, M. Balden, S. Elgeti, T. Schwarz-Selinger, S. Brezinsek, G. De Temmerman, in: PFMC Proceedings, Phys. Scr., 2019.

[6] K. Song, M. Thompson, G. De Temmerman, C.S. Corr, Nucl. Fusion 59 (2019) 096031.

[7] N. Ohno, D. Nishijima, S. Takamura, Y. Uesugi, M. Motoyama, N. Hattori, H. Arakawa, N. Ezumi, S.Krasheninnikov, A. Pigarov, U. Wenzel, Nucl. Fusion 41 (2001) 1055-1065.

[8] H. Greuner, B. Boeswirth, J. Boscary, P. McNeely, J. Nucl. Mater. 367-370 B (2007) 1444- 
1448.

[9] H. Greuner, H. Maier, M. Balden, B. Böswirth, S. Elgeti, K. Schmid, T. Schwarz-Selinger, J. Nucl. Mater. 455 (2014) 681-684.

[10] H. Greuner, H. Maier, M. Balden, C. Linsmeier, B. Böswirth, S. Lindig, P. Norajitra, S. Antusch, M. Rieth, J. Nucl. Mater. 442 (2013) S256-S260.

[11] H. Maier, H. Greuner, M. Balden, B. Böswirth, S. Elgeti, U. V. Toussaint, C. Linsmeier, Phys. Scr. T159 (2014).

[12] G. De Temmerman, T. Hirai, R.A. Pitts, Plasma Phys. Control. Fusion 60 (2018).

[13] R. Behrisch, W. Eckstein, Sputtering by Particle Bombardment: Experiments and Computer Calculations from Threshold to MeV Energies, 2007.

[14] R.A. Pitts, S. Carpentier, F. Escourbiac, T. Hirai, V. Komarov, S. Lisgo, A.S. Kukushkin, A. Loarte, M. Merola, A. Sashala Naik, R. Mitteau, M. Sugihara, B. Bazylev, P.C. Stangeby, J. Nucl. Mater. 438 (2013) S48-S56.

[15] H. Maier, H. Greuner, U. V. Toussaint, M. Balden, B. Böswirth, S. Elgeti, J. Nucl. Mater. 463 (2015) 337-340.

[16] T.J. Petty, M.J. Baldwin, M. Hasan, R.P. Doerner, J.W. Bradley, Nucl. Fusion 55 (2015) 1-11.

[17] S. Kajita, W. Sakaguchi, N. Ohno, N. Yoshida, T. Saeki, Nucl. Fusion 49 (2009) 1-6.

[18] R. Sakamoto, E. Bernard, A. Kreter, C. Martin, (2017) 13108.

[19] M. Miyamoto, S. Mikami, H. Nagashima, N. Iijima, D. Nishijima, R.P. Doerner, N. Yoshida, H. Watanabe, Y. Ueda, A. Sagara, J. Nucl. Mater. 463 (2014) 333-336.

[20] R. Sakamoto, E. Bernard, A. Kreter, N. Yoshida, Nucl. Fusion 57 (2017) 016040.

[21] Y.Z. Jia, W. Liu, B. Xu, S.L. Qu, T.W. Morgan, Nucl. Instruments Methods Phys. Res. Sect. B 
Beam Interact. with Mater. Atoms 438 (2019) 26-30.

[22] J.F. Ziegler, M.D. Ziegler, J.P. Biersack, Nucl. Instruments Methods Phys. Res. Sect. B Beam Interact. with Mater. Atoms 268 (2010) 1818-1823.

[23] C. Li, H. Greuner, Y. Yuan, G.N. Luo, B. Böswirth, B.Q. Fu, H.Y. Xu, Y.Z. Jia, W. Liu, J. Nucl. Mater. 455 (2014) 201-206.

[24] H. Greuner, H. Maier, M. Balden, B. Boeswirth, C. Linsmeier, J. Nucl. Mater. 417 (2011) 495-498. 